\title{
Difratometria de raios-X e análise térmica das frações granulométricas de caulins
}

\section{$X$-ray diffraction and thermal analysis of kaolins particle size fractions}

\author{
Patrícia dos Santos ${ }^{1}$; Antonio Carlos Saraiva da Costa ${ }^{2}$
}

\begin{abstract}
Resumo
Caulins são materiais geológicos comuns e apresentam elevada concentração de caulinita assim como a fração argila dos solos da região tropical e subtropical do Brasil. A caracterização de caulins é uma forma de avaliar a contribuição da caulinita em relação a importantes atributos químicos e mineralógicos dos solos. Neste trabalho foram avaliados quatro caulins (caulim comercial A (CCA), caulim comercial B (CCB), caulim rosa arenoso (CRA) e caulim verde arenoso (CVA)) no material original e nas frações granulométricas: areia $(200-53 \mu \mathrm{m})$, silte grosso $(53-20 \mu \mathrm{m})$, silte fino $(20-2 \mu \mathrm{m})$, argila grossa $(2-1$ $\mu \mathrm{m})$, argila média $(1-0,5 \mu \mathrm{m})$ e argila fina $(<0,5 \mu \mathrm{m})$. Os minerais foram identificados por difratometria de raios-X (DRX) e avaliados quanto a cristalinidade (caulinita e haloisita) por meio dos os índices de Hughes e Brown, Amigó, Bramão e pela temperatura de desidroxilação. O fracionamento físico foi eficiente na concentração de minerais em frações granulométricas específicas que não haviam sido identificados no material original. No CCA foi concentrado um mineral ainda não identificado nas mais frações finas, no CRA foi concentrado zircão no silte grosso e diferentes silicatos nas frações mais finas e no caulim CCB foram concentrados caulinita e um silicato nas frações, argila média e argila grossa. A estimativa por difração de raios-X superestimou a quantidade de caulinita e subestimou a de haloisita, quando comparada à quantificação por análise térmica gravimétrica. Os índices de cristalinidade apresentam comportamentos distintos em função da mineralogia de cada material, deste modo, correlações entre a cristalinidade da caulinita e/ou haloisita e outras variáveis podem ser comprometidas, principalmente em materiais com origens geológicas distintas.
\end{abstract}

Palavras-chave: Caulinita. Índice de cristalinidade. DRX.

\begin{abstract}
Kaolins are common geological materials and have high concentrations of kaolinite as well as the clay fraction of tropical and subtropical soils of Brazil. The characterization of kaolin is a proxy of assessing the contribution of kaolinite to important soil chemical and mineralogical attributes. This study evaluated four kaolins (commercial kaolin A (CCA), commercial kaolin B (CCB), pink sandy kaolin A (CRA) and green sandy kaolin A (CVA)) in the original form and after particle size separation into: sand (200-53 $\mathrm{mm})$, coarse silt $(53-20 \mu \mathrm{m})$, fine silt $(20-2 \mu \mathrm{m})$, large clay $(2-1 \mu \mathrm{m})$, medium clay $(1-0.5 \mu \mathrm{m})$ and fine clay $(<0.5 \mu \mathrm{m})$ fractions. The minerals were identified by X-ray diffraction (XRD) and evaluated for crystallinity (kaolinite and halloysite) through indexes Hughes and Brown, Amigó, Bramão and the dehydroxylation temperature. The physical fractionation was efficient to concentrate minerals in specific size fractions which were not identified in the original material. In CCA kaolin was concentrated one
\end{abstract}

\footnotetext{
${ }^{1}$ Mestranda do Programa de Pós-Graduação em Agronomia, Universidade Estadual de Maringá, Avenida Colombo 5790, MaringáPR, CEP 87020-190, patriciasantos2007@gmail.com

${ }^{2}$ Professor Associado III da Universidade do Estadual de Maringá - Departamento de Agronomia, acscosta@uem.br.
} 
mineral which remains unidentified in fine fractions, in kaolin CRA, zircon was concentrated in the coarse silt and different silicates in the fine fractions, in kaolin CCB were concentrated kaolinite and a silicate in the medium and coarse clay fractions. The estimate by X-ray diffraction overestimated the amount of kaolinite and halloysite underestimated when compared to quantification by thermal gravimetric analysis The crystallinity index exhibit different behaviors depending on the mineralogy of each material, thus the correlation between the crystallinity of kaolinite and / or halloysite and other variables, may be compromised, especially in materials with distinct geological origins.

Keywords: Kaolinite. Crystallinity index. XRD.

\section{Introdução}

O termo "caulim" é derivado da palavra kauling, nome dado a uma colina próxima a Jauchau $\mathrm{Fu}$, no norte da China, onde por muitos séculos os chineses exploram este material para a produção da porcelana (GRIM, 1968).

A caulinita é principal constituinte do caulim (MURRAY, 2007) que normalmente ocorre associada a outros minerais sob a forma de impurezas (quartzo, mica, feldspatos e óxidos de Fe e Ti), porém em muitas regiões do Brasil os caulins se constituem de uma mistura de caulinita e haloisita (WILSON; SOUZA SANTOS; SOUZA SANTOS, 2006).

Em função de suas propriedades físicas e químicas, a caulinita pode ser usada em um grande número de aplicações industriais, dentre elas a produção de papel, borracha, tintas, fármacos e fertilizantes. A haloisita por sua vez apresenta um alto valor comercial na indústria de cerâmica devido ao alto brilho e translucidez que proporciona aos seus produtos (MURRAY, 2007).

O Brasil é o sexto maior produtor de caulim, com aproximadamente 2,4 milhões de toneladas em 2010 , cerca de $8 \%$ da produção mundial, que é de 31 milhões de toneladas (INSTITUTO BRASILEIRO DE MINERAÇÃO, 2011).

No Brasil os principais depósitos de caulins são sedimentares e se localizam nos Estados do Amazonas, Pará e Amapá, outros depósitos relativamente importantes são encontrados nos Estados de Minas Gerais, Paraíba, São Paulo,
Goiás, Santa Catarina e Paraná, porém são caulins primários e apresentam menor qualidade industrial (LUZ et al., 2005).

A caulinita é o filossilicato mais abundante nos solos altamente intemperizados (WHITE; DIXON, 2002) enquanto a haloisita é comum em solos pouco desenvolvidos formados a partir de cinzas vulcânicas (DIXON; MCKEE, 1974; DIXON, 1989).

A caulinita e a haloisita- $7 \AA \AA$ apresentam padrões de difração de raios- $X$ similares, tornando a distinção entre ambas, praticamente impossível por esta técnica na ausência de metodologias acessórias, no entanto quando a intensidade do reflexo a 0,445 $\mathrm{nm}$ é a metade ou mais do que aquela atribuída ao reflexo a $0,72 \mathrm{~nm}$ é provável a presença de haloisita, visto que as caulinitas se orientam preferencial no plano $\mathrm{d}_{001}$ (BRINDLEY, 1961).

A haloisita-10 Å pode facilmente ser diferenciada da caulinita na ausência de micas devido à presença de um reflexo basal a $1 \mathrm{~nm}$, no entanto sob condições ambientais ou de moderado aquecimento $\left(40^{\circ} \mathrm{C}\right)$, esta pode ser rapidamente convertida em haloisita-7 Å (KOHYAMA; FUKUSHIMA; FUKAMI, 1978).

Deste modo a diferenciação de caulinitas e haloisitas é necessária e pode ser feita por meio da solvatação com formamida $\left(\mathrm{CH}_{3} \mathrm{NO}\right)$, já que a expansão da haloisita de $0,72 \mathrm{~nm}$ para $1,0 \mathrm{~nm}$ é rápida, enquanto a da caulinita não ocorre antes de 4 horas (CHURCHMAN et al., 1984).

Embora outros métodos tenham sido testados para diferenciar a caulinita e a haloisita, dentre 
eles a solvatação com etileno glicol, a utilização da formamida é mais comum devido a sua maior eficiência e praticidade (JOUSSEIN et al., 2006).

Os padrões de DRX da caulinita e haloisita são frequentemente utilizados para o cálculo de índices de cristalinidade, característica frequentemente associada a importantes atributos físicos e químicos de caulins, dentre eles a área superficial específica externa e capacidade de troca catiônica (MURRAY; LYONS, 1960).

Considerando a importância da caulinita e haloisita em solos e materiais geológicos com fins industriais, este trabalho teve por objetivo caracterizar por difratometria de raios-X e análise térmica diferentes caulins na sua forma original $\mathrm{e}$ em diferentes frações granulométricas.

\section{Materiais e Métodos}

\section{Materiais}

Foram avaliados quatro caulins: dois comerciais, caulim comercial A (CCA) e caulim comercial B (CCB) e dois de origem sedimentar, fornecidos pela Mineração Aruanã-Pr, caulim rosa arenoso (CRA) e caulim verde arenoso (CVA).

\section{Separação das frações}

Os caulins sem nenhum tratamento prévio foram fracionados em areia $(200-53 \mu \mathrm{m})$, silte grosso (53$20 \mu \mathrm{m})$, silte fino $(20-2 \mu \mathrm{m})$, argila grossa $(2-1 \mu \mathrm{m})$, argila média $(1-0,5 \mu \mathrm{m})$ e argila fina $(<0,5 \mu \mathrm{m})$.

Para o fracionamento utilizou-se $50 \mathrm{~g}$ de cada material que permaneceram sob agitação mecânica por $(8 \mathrm{~h})$ em frascos $1 \mathrm{~L}$ na presença de $\mathrm{NaOH} 0,02$ mol L-1 como agente dispersante. Por tamisamento foram separadas as frações silte grosso (retido em peneira com malha de $0,020 \mathrm{~mm}$ ) e areia (retido em peneira com malha de $0,053 \mathrm{~mm}$ ) e por meio de sifonamento, depois da sedimentação, segundo a lei de Stokes, foram separadas as frações argila grossa, argila média e argila fina. A fração silte fino foi obtida por diferença entre os dois métodos.

As frações mais grossas (areia, silte grosso e silte fino) depois de separadas, foram secas em estufa a $60^{\circ} \mathrm{C}$ até peso seco, enquanto as frações mais finas (argila fina, argila média e argila grossa) foram floculadas com $\mathrm{MgCl}_{2} 0,1 \mathrm{M}$, lavadas com água deionizada para remover o excesso de $\mathrm{Mg}^{2+} \mathrm{e} \mathrm{Cl}^{-1}$, congeladas em $\mathrm{N}_{2}$ líquido e liofilizadas (JACKSON, 1975) em um equipamento Christ Alpha 1-2.

\section{Difratometria de raios- $x$ (DRX)}

As amostras das diferentes frações e do material original, em pó, foram submetidas à difração de raios-x num equipamento Shimadzu XRD 6000 com fonte de $\mathrm{Cu}$ e monocromador de cristal de grafite. As amostras foram analisadas no modo passo na amplitude angular de $2^{\circ}$ a $70^{\circ} 2 \theta$, a cada $0,02^{\circ} 2 \theta ; 0,6 \mathrm{~s}$ por passo nas frações mais grossas e $1,0 \mathrm{~s}$ por passo nas mais frações finas.

Os difratogramas foram analisados e os minerais identificados utilizando os planos de difração conforme Moore e Reynolds JR. (1989) e Whitting e Alardice (1986) para os silicatos e Costa e Bigham (2009) para os óxidos de ferro.

Para diferenciar caulinitas e haloisitas, amostras da fração argila $(<2 \mu \mathrm{m})$ foram solvatadas com formamida (CHURCHMAN et al., 1984) e analisadas por DRX nas mesmas condições descritas anteriormente para as frações mais finas, na amplitude de $2^{\circ}$ a $17^{\circ} 2 \theta$.

A estimativa da quantidade dos minerais por DRX foi calculada considerando que a área dos reflexos é proporcional a quantidade do mineral presente na amostra.

\section{Análise térmica}

Os dados da análise térmica gravimétrica (ATG) e análise térmica diferencial (ATD) foram obtidos num equipamento Shimadzu, TA-50, operando em 
atmosfera de $\mathrm{N}_{2}$, num fluxo de $20 \mathrm{~mL} \mathrm{min.}{ }^{-1}$ e taxa de aquecimento de $20^{\circ} \mathrm{C} \mathrm{min.}{ }^{-1}$, em amostras com cerca de $6 \mathrm{mg}$. A quantificação da caulinita em mistura com a haloisita foi calculada utilizando os dados de perda de massa associada às reações de desidroxilação da caulinita e haloisita (KARATHANASIS, 2008). Os dados usados para a quantificação dos minerais por ATD assim como a estimativa por DRX foram processados no programa GRAMS $8 \circledR$.

\section{Grau de Cristalinidade da Caulinita e Haloisita}

Calculou-se o índice de cristalinidade de Hughes e Brown (1979) utilizando a relação entre a altura do reflexo referente ao plano $\mathrm{d}_{020}$ e a altura do "background" entre os reflexos referentes aos planos $\mathrm{d}_{-131}$ e $\mathrm{d}_{003}$ pela equação 1 .

$$
H \in B=\frac{1,93 \mathrm{~h} 1}{\mathrm{~h} 2}
$$

O índice de Amigó et al. (1987) equivale a largura a meia altura (LMA) do reflexo $\mathrm{d}_{001}$.

O índice de Bramão et al. (1952) foi calculado utilizando a relação de inclinação $(\alpha / \beta)$ entre os lados de baixa e alta temperatura dos picos endotérmicos referentes à desidroxilação da caulinita e haloisita.

\section{Resultados e Discussões}

\section{Identificação dos minerais}

O CCA (material original) apresenta caulinita, mica e haloisita (Figura 1A). No entanto, nas frações mais finas foi encontrado um mineral a 0,568 $\mathrm{nm}$, que apresenta padrões de difração de raios-X (Figura 2A, 2B e 2C), semelhantes aqueles da alunita (sulfato de alumínio) e da crandalita (fosfato de cálcio e alumínio), porém é mais provável a presença da alunita, já que a sua associação com caulinitas em depósitos de caulim é comum.
Figura 1 - Difratogramas de raios- $X$ do caulim comercial A, (A), caulim rosa arenoso (B), caulim verde arenoso (C) e caulim comercial $B$ (D) no material original, sem fracionamento. C: caulinita, H: haloisita, M: mica, G: glauconita ou celadonita, Q: quartzo, $\mathrm{Ru}$ : rutilo, $\mathrm{P}$ : pirofilita, D: diáspora.

A

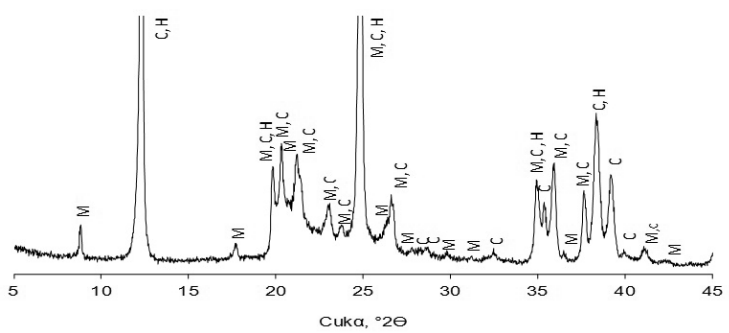

B

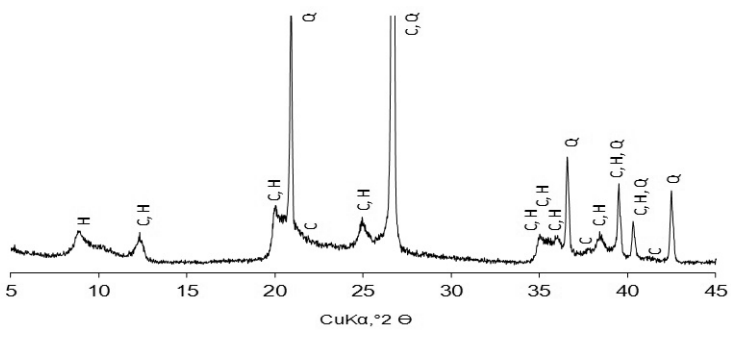

C

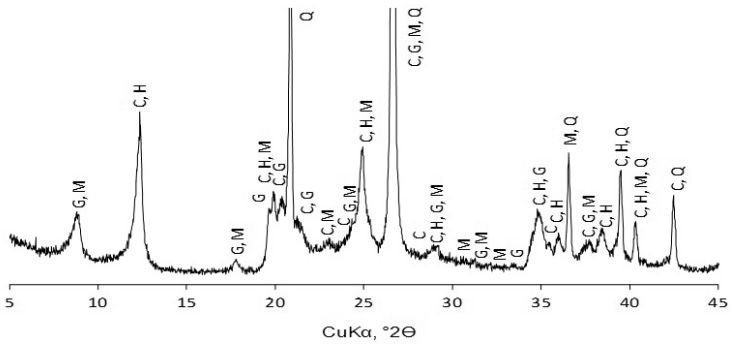

$\mathrm{D}$

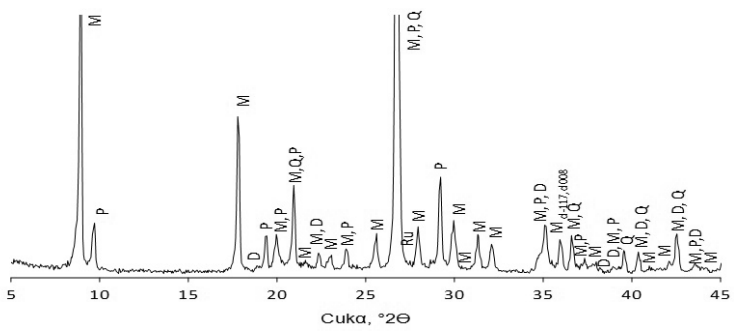

Fonte: Os autores. 
Figura 2 - Difratogramas de raios- $X$ do caulim comercial A (CCA) nas frações, argila fina (A), argila média (B), argila grossa (C), silte fino (D) e silte grosso (E). C: caulinita, H: haloisita, M: mica, Q: quartzo, N.I: mineral não identificado.

A

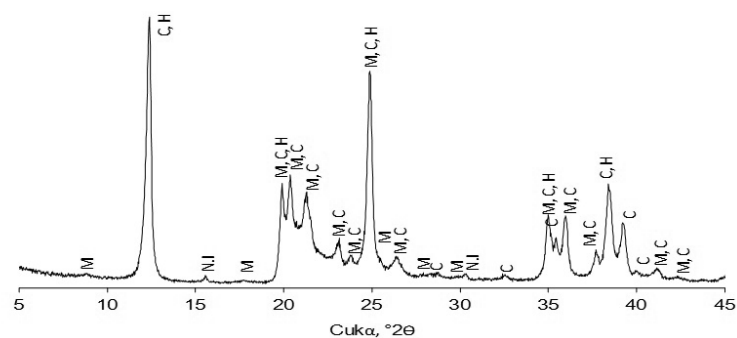

B

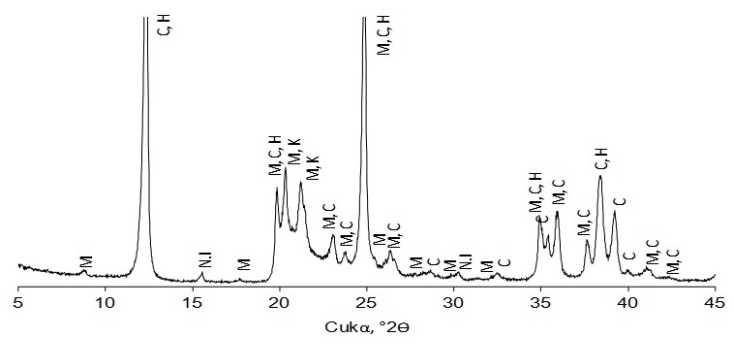

C

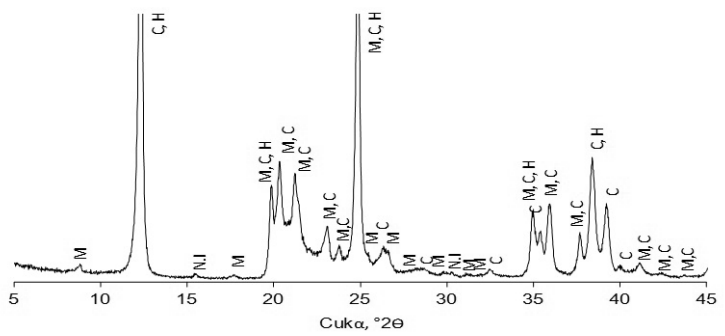

D

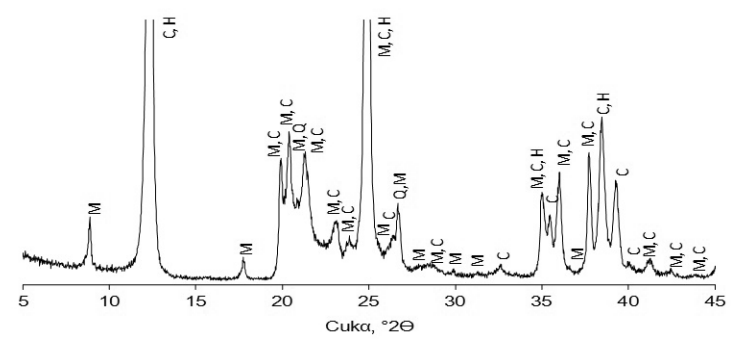

E

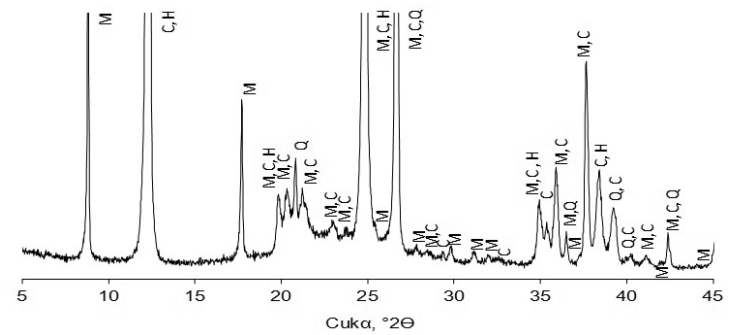

Fonte: Os autores.
Figura 3 - Difratogramas de raios-X do caulim rosa arenoso (CRA) nas frações, argila fina (A), argila média (B), argila grossa (C), silte fino (D), silte grosso (E) e areia (F). C: caulinita, H: haloisita, Q: quartzo, Ru: rutilo, Zr: zircão, N.I: mineral não identificado.

A

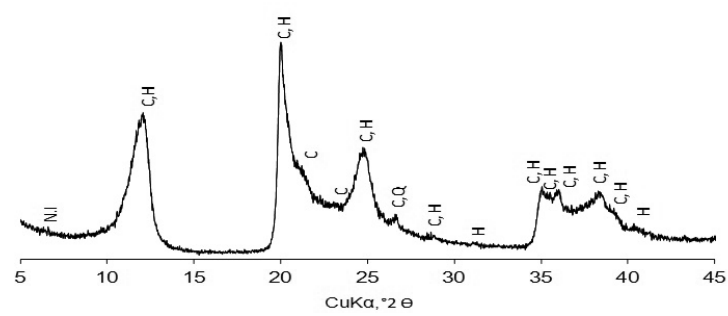

B

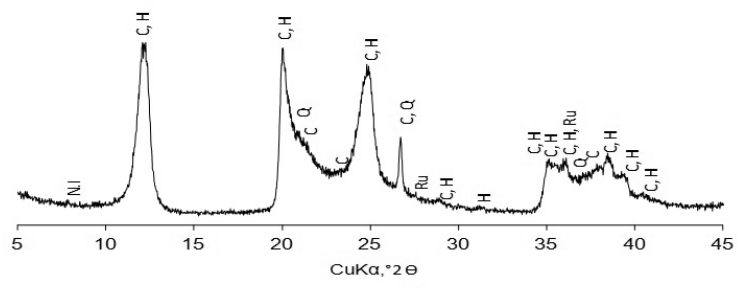

C

D
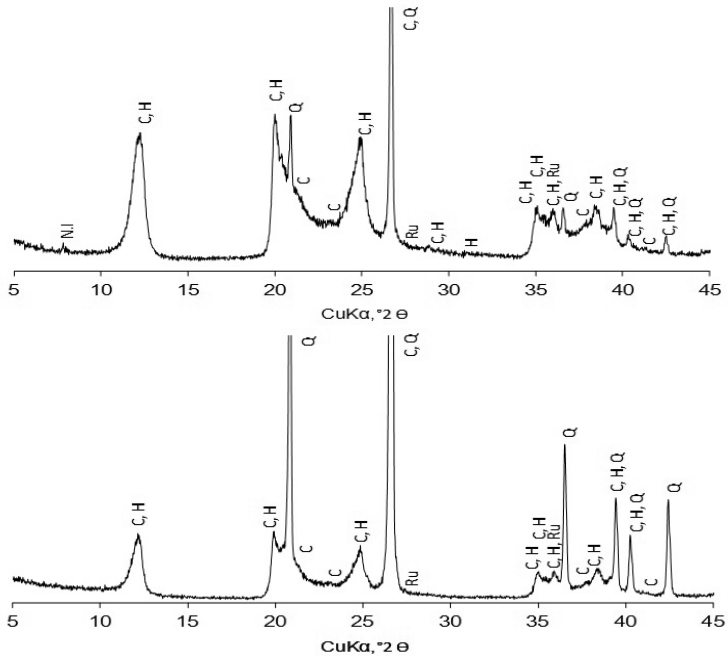

E

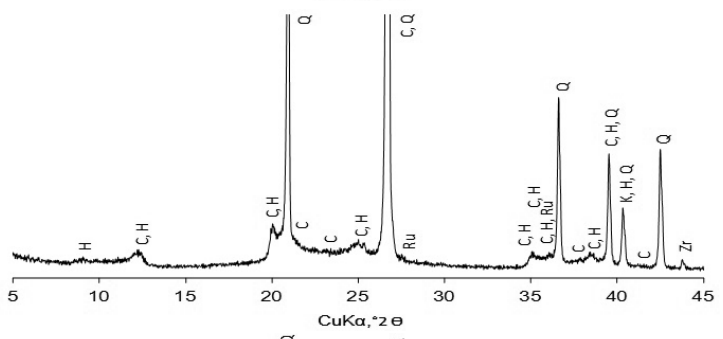

F

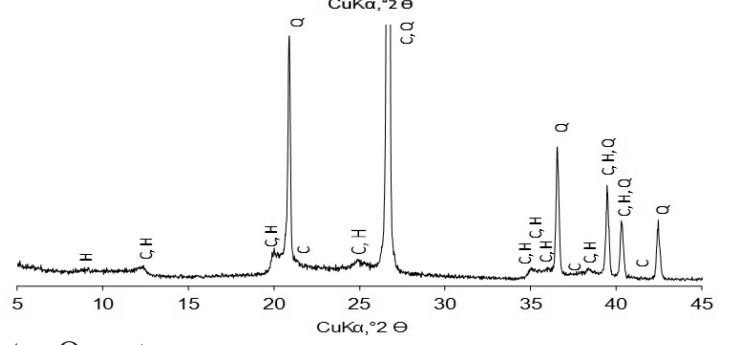

Fonte: Os autores. 
O CRA (material original) apresenta caulinita, quartzo e haloisita (Figura 1B). No entanto nas frações, argila média e argila grossa foram identificados, rutilo e um silicato a $1,138 \mathrm{~nm}$ (Figura 3B e 3C) e possivelmente uma esmectita identificada por um pequeno reflexo a $1,38 \mathrm{~nm}$, na fração argila fina (Figura 3A).

Nas frações mais grosseiras ainda foi possível identificar rutilo no silte fino e no silte grosso e zircão no silte grosso (Figura 3D, 3E e 3F). Nas frações silte grosso e areia, assim como no material original a haloisita pode ser identificada por meio de uma banda na região entre 0,7 e 1,0 nm (Figuras 1A, 3E e 3F), comportamento típico característico de um processo de desidratação incompleta (JOUSSEIN et al., 2006).

O caulim verde (material original) é constituído de caulinita, haloisita, quartzo e micas (Figura 1C). Uma das micas encontradas neste material possivelmente é a glauconita ou celadonita, cuja presença é mais evidente na fração argila fina (Figura 4A), onde é possível encontrar um reflexo a $0,453 \mathrm{~nm}\left(\mathrm{~d}_{020}\right)$ que tem sua intensidade diminuída nas outras frações, onde este reflexo dá lugar àquele a $0,445 \mathrm{~nm}$, que pertence à outra mica assim como a caulinita e haloisita.

A distinção entre a glauconita e celadonita é difícil por DRX e seriam necessárias análises adicionais como a espectroscopia de infravermelho (BUCKLEY et al., 1978), porém como esse material é de origem sedimentar é possível que o mineral em questão seja uma glauconita, visto que celadonita é um produto comum do intemperismo de basaltos em ambientes marinhos (BAKER et al., 2012; MCRAE, 1972). Além destes minerais foram encontradas, bassanita e calcita na argila média e argila grossa (Figura 4B e 4C).

O CCB (material original) apresenta quartzo, mica, pirofilita e diáspora (Figura 1D) ao contrário do esperado, já que este material seja comercializado como caulim. A presença da caulinita neste material é limitada pequenos resquícios nas frações argila média e grossa (Figura 5B e 5C).

No entanto foi identificado um silicato na argila média e argila grossa (Figura 5B e 5C), que pode ser uma esmectita ou uma vermiculita, rutilo no silte fino e grosso (Figura 5D e 5E) e magnetita na argila fina, argila média e argila grossa (5A, 5B e 5C). A presença da magnetita neste material foi confirmada durante o fracionamento, onde foi notado que partículas de coloração escura eram atraídas por um campo magnético (imã).

A utilização de formamida $\left(\mathrm{CH}_{3} \mathrm{NO}\right)$ para diferenciar a caulinita e a haloisita mostrou que os caulins são muito diferentes com relação à quantidade de haloisita. O CCA apresentou uma pequena porcentagem de haloisita em relação à caulinita na fração $<2 \mu \mathrm{m}(1 \%)$, ao contrário do CVA e do CRA onde o teor de haloisita é 5,26 e $82,58 \%$, respectivamente.

Quantificação da caulinita e haloisita por análise térmica (TGA) e estimativa por difratometria de raios- $X(D R X)$

Os teores de caulinita e haloisita quantificados por ATG e estimados por DRX para a (Tabela 1) apresentaram correlação linear positiva, com um coeficiente de regressão de 91,71 \% (Figura 6 A). No entanto, ao analisarmos cada material isoladamente, o coeficiente de regressão passa a ser $95,84 \%$ e $51,07 \%$, respectivamente, para o CRA e CCA (Figura 6B).

O menor valor atribuído ao coeficiente de regressão para a relação entre os teores de caulinita e haloisita quantificados ATG e estimados por DRX para a o CCA se deve a fração silte fino, que aparentemente teve o valor atribuído ao teor de caulinita e haloisita subestimado pela analise térmica.

Durante a deconvolução dos picos da caulinita e da mica pelo programa GRAMS $8 \AA$, a área atribuída à mica pode ser sido superestimada devido 
à pequena quantidade deste mineral nesta fração quando comparada ao silte grosso, onde é possível distinguir visualmente os dois picos e os valores quantificados por ATG e estimados por DRX são mais próximos (Tabela 1).

Os valores estimados por DRX para o CCA são maiores do que aqueles obtidos por ATG, provavelmente devido à orientação preferencial da caulinita no plano $\mathrm{d}_{001}$ durante a preparação das amostras para análise de DRX.

Ao contrário do CCA, o CRA que apresenta menores valores para a estimativa de DRX na maioria das frações ou valores próximos para as ambas às determinações, provavelmente devido às características intrínsecas aos padrões de difração da haloisita, que apresenta reflexos para o plano $\mathrm{d}_{001}$ menos intensos, que aqueles referentes ao plano $\mathrm{d}_{100}$ (BRINDLEY, 1961).

A caulinita e haloisita se acumularam preferencialmente nas frações mais finas ao contrário do quartzo que tende a se concentrar nas frações mais grossas. As micas aparentemente podem se acumular tanto nas frações mais finas (mica secundária) quanto nas mais grossas (mica primária) (Tabela 1).

A mica encontrada no caulim CCA apresenta distribuição crescente em direção às frações mais grossas, ao contrário daquela encontrada no CVA que se acumula nas frações mais finas (Tabela 1).

A mica encontrada no CCA é provavelmente a mesma em todas as frações, particionada a partir das frações mais grossas por meio do intemperismo físico, com pequenas diferenças químicas da mica macrocristalina (KODAMA; BRYDON, 1968), já aquela acumulada nas frações mais finas do CVA é uma mica secundária (glauconita ou celadonita) que aparentemente foi formada durante o processo de intemperismo.
Figura 4 - Difratogramas de raios- $X$ do caulim verde arenoso (CVA) nas frações, argila fina (A), argila média (B), argila grossa (C), silte fino (D), silte grosso (E) e areia (F). C: caulinita, G: glauconita e/ou celadonita, M: mica, Ba: bassanita, Ca: calcita, Q: quartzo.

A

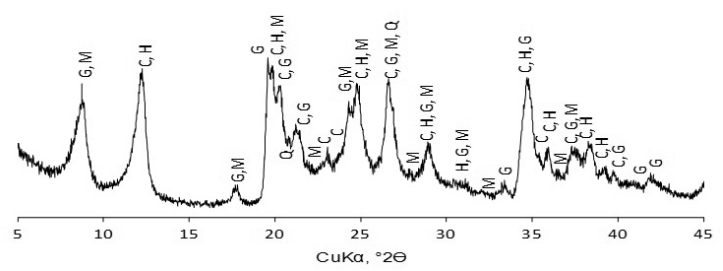

B

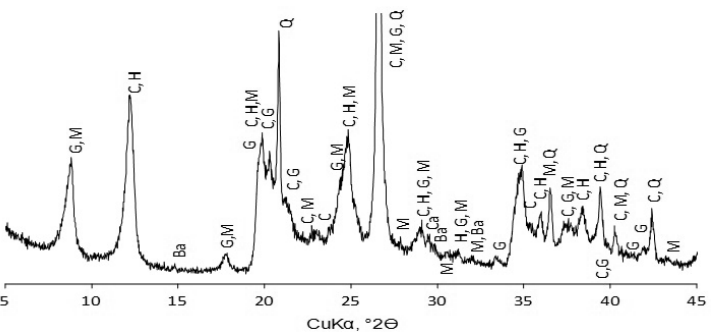

C

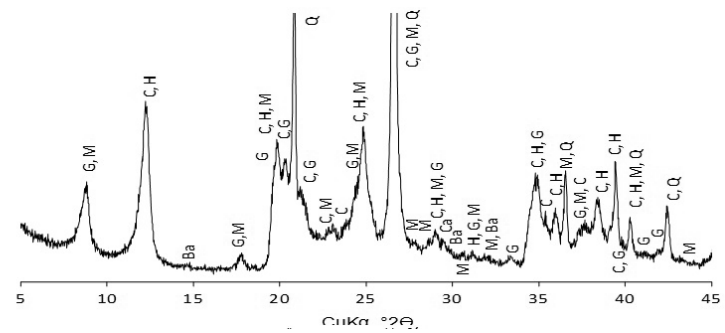

D

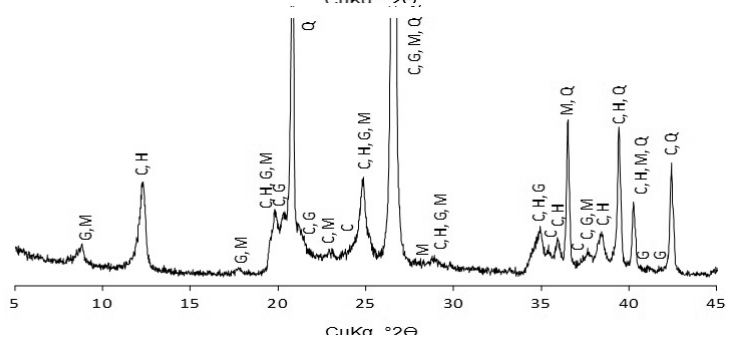

E

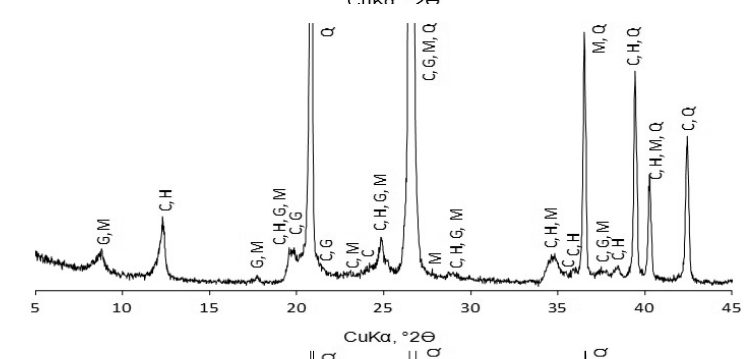

$\mathrm{F}$

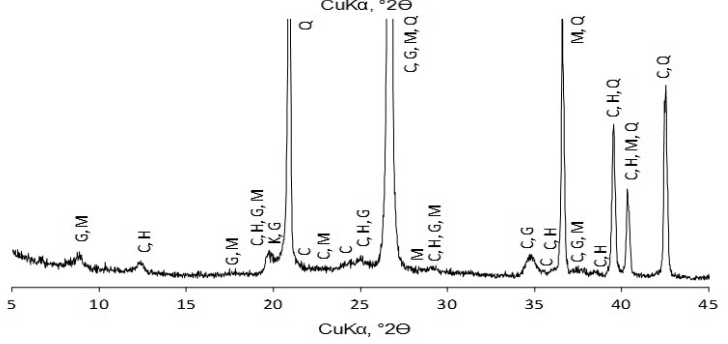

Fonte: Os autores. 
Figura 5 - Difratogramas de raios- $X$ do caulim comercial B (CCB) nas frações, argila fina (A), argila média (B), argila grossa (C), silte fino (D), silte grosso (E) e areia (F). M: mica, P: pirofilita, D: diáspora, Q: quartzo, Mg: magnetita, S: silicato, Ru: rutilo.

A
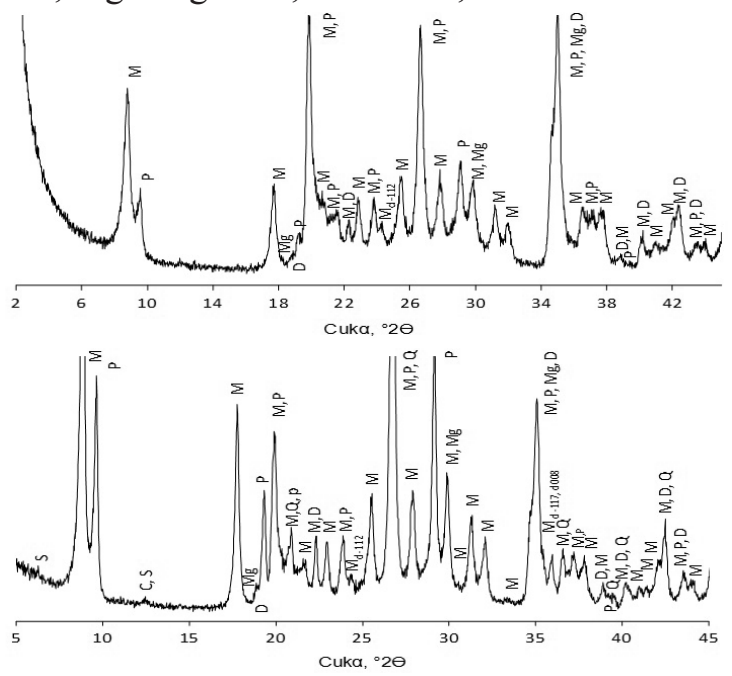

C

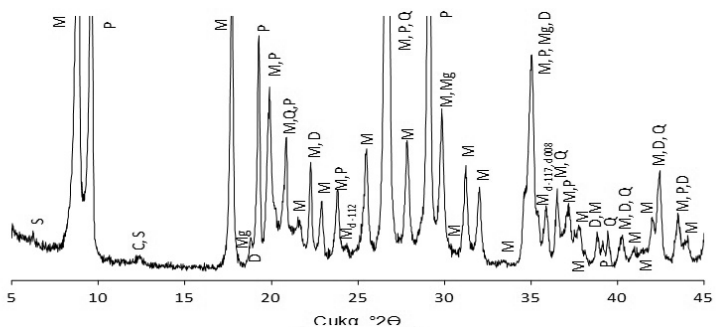

D

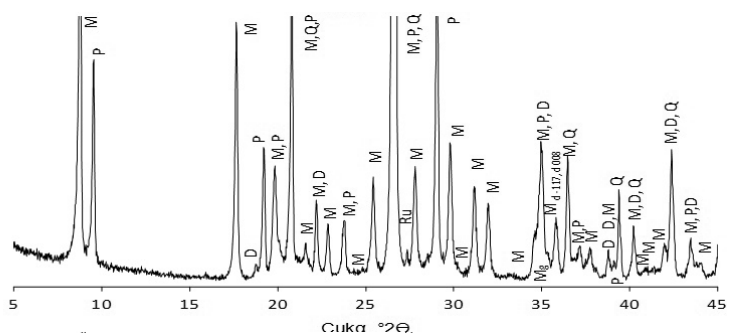

E

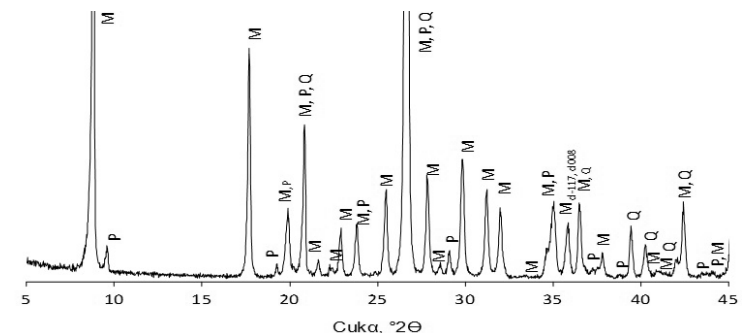

F

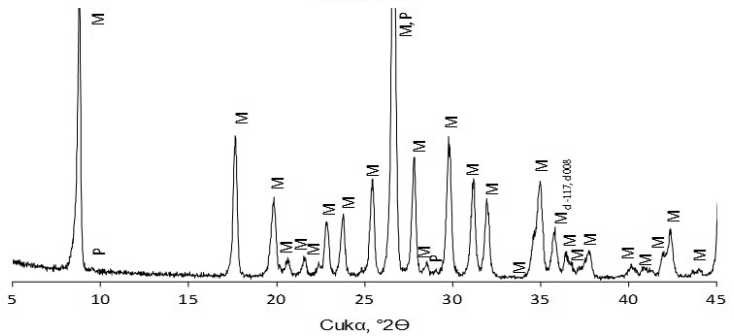

Fonte: Os autores.
O CCB apresenta duas micas com características cristalográficas distintas, uma concentrada na fração areia e outra na fração argila fina (Tabela 2).

Essa hipótese pode ser verificada pela presença de um reflexo a $0,365 \mathrm{~nm}\left(\mathrm{~d}_{112}\right)$ nas frações mais finas (Figura 4A, 4B e 4C) que se encontra ausente nas frações mais grossas (Figura 4D, 4E e 4F) e a ausência de um reflexo a 0,249 $\mathrm{nm}\left(\mathrm{d}_{117}\right.$ e $\left.\mathrm{d}_{008}\right)$, na fração argila fina, que se encontra presente nas demais frações (Figura 4A).

Figura 6- Correlação entre a estimativa de caulinita e haloisita por DRX e quantificação por ATG, nas amostras de caulins CCA e CRA (A) simultaneamente e para a amostra CCA e CRA, separadamente (B).

A

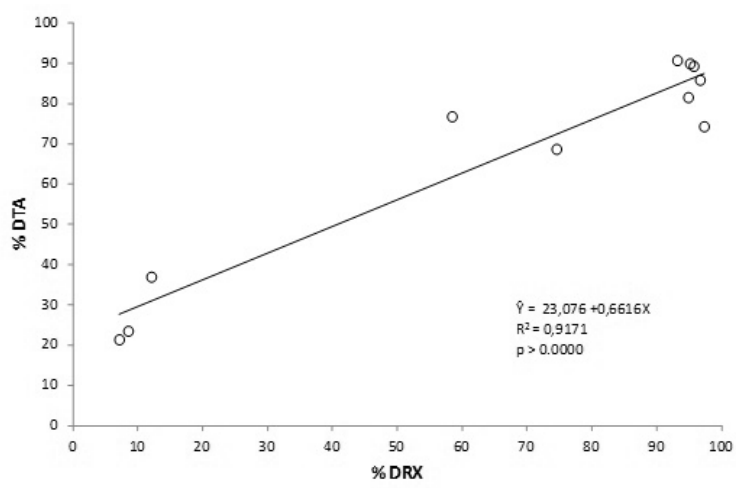

B

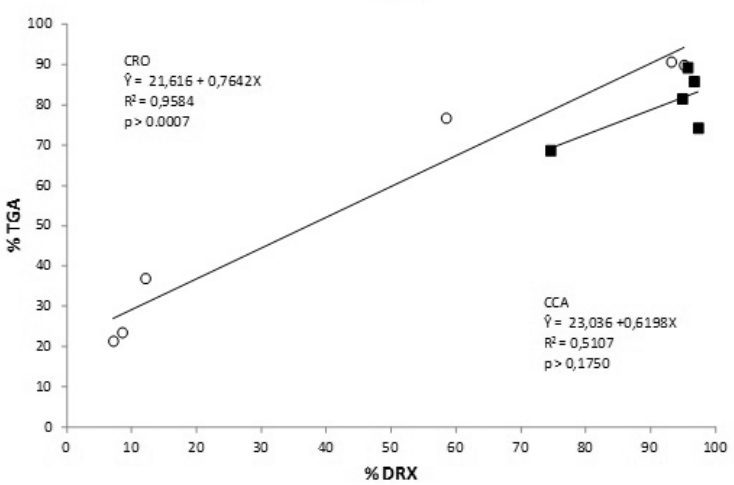

Fonte: Os autores.

Estas variações nos padrões de DRXs caracterizam mudanças cristalográficas que podem estar ocorrendo devido ao processo de intemperismo em uma mica primária ou a neoformação de uma mica secundária que se concentra na fração argila fina. 


\section{Cristalinidade}

Caulinitas geralmente são muito mais cristalinas que haloisitas e como consequência, o CCA é muito mais cristalino que o CRA em todas as frações, independente do índice de cristalinidade utilizado na avaliação (Tabela 2).

Todos os índices de cristalinidade utilizados neste trabalho, Hughes e Brown (1979), índice de Bramão et al. (1952) e índice de Amigó et al. (1987) e a temperatura de desidroxilação, não são específicos para a caulinita ao contrário do índice de Liètard (1977), porém devido à predominância de haloisita em relação a caulinita no CRA, a pequena quantidade de caulinita $(<20 \%)$ em algumas frações do CRA, assim como a presença de quartzo no CRA e no CCA este procedimento tornou-se inviável (APARÍCIO; GALÁN, 1999).

Os valores obtidos representam uma média da cristalinidade da caulinita e haloisita presentes em cada fração em função da quantidade destes minerais.

Os valores atribuídos ao índice de Hughes e Brown (1979) e a temperatura de desidroxilação para o CCA, ao índice de Bramão et al. (1952) e Amigó et al. (1987) para todas frações onde foram calculados, com exceção do valor atribuído ao índice de Hughes e Brown (1979) para a fração silte grosso do CCA, variam em função do tamanho de partícula, indicando que a cristalinidade aumenta proporcionalmente com o tamanho de partícula (VELHO; GOMES, 1991) ao contrário dos valores encontrados por Ormsby, Shartsis e Woodside (1962). O valor obtido para o silte grosso foi menor do que o esperado para o índice de Hughes e Brown (1979), devido à presença de maiores concentrações de mica nesta fração, quando comparada às outras. Este mineral apresenta um reflexo na mesma posição $(0,445$ $\mathrm{nm}$ ), daquele utilizado para calcular o parâmetro h1 (Equação 1), que pode ter sido subestimado.

O CRA não apresenta o comportamento esperado para o índice de Hughes e Brown (1979) devido à presença de um reflexo referente ao quartzo $(0,245 \mathrm{~nm})$, na mesma região utilizada para calcular parâmetro h2 (Equação1). Aparentemente as maiores concentrações deste mineral nas frações mais grossas teriam contribuído para subestimar o valor atribuído a cristalinidade.

Ao contrário do esperado as partículas menores apresentam maiores temperatura de desidroxilação para o CRA. Contudo esse comportamento pode ser explicado pelas quantidades de caulinita e haloisita que decrescem das frações mais finas para as frações mais grossas (Tabela 1).

Segundo Cavalheiro et al. (1995) a massa de um determinado mineral é um fator determinante sobre a temperatura de desidroxilação, pois menores massas podem favorecer a homogeneização de temperatura mais rapidamente e deslocar a temperatura de desidroxilação para a esquerda, justificando desde modo a inversão das temperatura de desidroxilação no CRA.

O CCA apresenta um comportamento contrário àquele apresentado pelo CRA com relação as temperatura de desidroxilação, embora apresente um comportamento similar quanto às quantidades de caulinita, contudo as diferenças entre as quantidades são menores (Tabela 1), além disso, a mica presente nestas amostras pode ter contribuído para aumentar a temperatura de desidroxilação, visto que o pico endotérmico deste mineral era posterior e próximo ao da caulinita, sendo na maioria das frações, impossível separálos visualmente. 
Tabela 1 - Estimativa das fases mineralógicas por difratometria de raios-X DRX e quantificação da caulinita e haloisita por análise térmica gravimétrica (TGA) no CCA e CRO

\begin{tabular}{|c|c|c|c|c|c|c|c|}
\hline \multirow{2}{*}{ Materiais } & \multirow{2}{*}{ Minerais } & \multirow{2}{*}{ Areia } & \multicolumn{2}{|l|}{ Silte } & \multicolumn{3}{|l|}{ Argila } \\
\hline & & & Grosso & Fino & Grossa & Média & Fina \\
\hline \multirow[t]{5}{*}{$\mathrm{CCA}$} & $\mathrm{C} / \mathrm{H}$ & n.d. & 74,54 & 97,29 & 95,69 & 96,67 & 94,84 \\
\hline & $\mathrm{C} / \mathrm{H}^{* *}$ & n.d. & 68,7 & 74,31 & 89,29 & 85,85 & 81,55 \\
\hline & $\mathrm{M}$ & n.d. & 9,18 & 2,42 & 3,11 & 1,56 & 2,31 \\
\hline & N.I & n.d. & - & - & 1,20 & 1,77 & 2,85 \\
\hline & Q & n.d. & 16,28 & 0,29 & - & - & - \\
\hline \multirow[t]{5}{*}{ CRA } & $\mathrm{C} / \mathrm{H}$ & 8,51 & 6,83 & 12,07 & 58,44 & 93,15 & 95,12 \\
\hline & $\mathrm{C} / \mathrm{H}^{* *}$ & 23,55 & 21,42 & 36,98 & 76,78 & 90,73 & 89,92 \\
\hline & $\mathrm{Q}$ & 91,49 & 93,17 & 87,93 & 41,56 & 6,85 & 4,88 \\
\hline & $\mathrm{Zr}$ & - & $* * *$ & - & - & - & - \\
\hline & $\mathrm{Ru}$ & - & $* * *$ & $* * *$ & $* * *$ & $* * *$ & - \\
\hline \multirow[t]{4}{*}{ CVA } & $\mathrm{C} / \mathrm{H}$ & 1,16 & 4,00 & 8,76 & 29,11 & 26,78 & 56,31 \\
\hline & $\mathrm{M} / \mathrm{G}$ & 1,50 & 2,00 & 1,92 & 12,64 & 17,45 & 43,69 \\
\hline & $\mathrm{Ba} / \mathrm{Ca}$ & - & - & - & $* * *$ & $* * *$ & - \\
\hline & $\mathrm{Q}$ & 97,34 & 94,00 & 89,32 & 58,25 & 55,77 & $* * *$ \\
\hline \multirow[t]{8}{*}{ CCB } & $\mathrm{C} / \mathrm{H}$ & - & - & - & 0,99 & 0,65 & - \\
\hline & $\mathrm{P}$ & - & 5,35 & 17,09 & 36,83 & 28,83 & 24,19 \\
\hline & $\mathrm{M}$ & 100 & 47,82 & 24,78 & 54,31 & 66,77 & 75,81 \\
\hline & $\mathrm{D}$ & - & - & 5,24 & 3,36 & 3,75 & $* *$ \\
\hline & Q & - & 46,83 & 52,35 & 4,51 & - & - \\
\hline & $\mathrm{Ru}$ & - & - & 0,54 & - & - & - \\
\hline & $\mathrm{Mg}$ & - & - & - & $* * *$ & $* * *$ & $* * *$ \\
\hline & $\mathrm{S}$ & - & - & - & $* * *$ & $* * *$ & - \\
\hline
\end{tabular}

*C: caulinita, H: haloisita, M: mica, N.I: mineral não identificado, Q: quartzo, G: glauconita, Ca: calcita, Ba: bassanita, Ru: rutilo, Zr: zircão, P: pirofilita, D: diáspora, Mg: magnetita. **quantificação por ATD; *** embora o reflexo característico do mineral tenha sido encontrado a área do pico não foi calculada pelo programa GRAMS $8 \AA$.

Fonte: Os autores.

Segundo a classificação de Smykatz-Kloss (1974) quanto à cristalinidade com base na temperatura de desidroxilação todas as frações dos dois materiais são consideradas extremamente desordenadas, com exceção do silte grosso do CCA que pode ser classificado como fortemente desordenado, porém como a massa utilizada na ATG era muito pequena $(6 \mathrm{mg})$, em comparação com as $100 \mathrm{mg}$ normalmente utilizadas para este tipo de classificação (LOMBARDI, 1987; SMYKATZKLOSS, 1982) a temperatura de desidroxilação foi subestimada e consequentemente tornou tal classificação inválida, sendo pertinente apenas a comparação entre e dentre os materiais com base na temperatura de desidroxilação.

O índice de Amigó et al. (1987), ou seja, a largura a meia altura do plano 001 (LMA) é inversamente proporcional ao diâmetro médio do cristalito (DMC), partículas maiores apresentam menores valores de LMA, o que esta de acordo com os valores encontrados e permite classificar as caulinitas encontradas na fração argila grossa, silte fino e silte grosso do CCA como ordenadas (LMA < 0,3) (APARÍCIO; GALÁN, 1999).

O índice Bramão et al. (1952) se comportou da forma esperada em todas as frações onde foi calculado. Segundo KARATHANASIS (2008) este índice tem sido utilizado para distinguir caulinitas e haloisitas, já que haloisitas e caulinitas pobremente cristalinas geralmente exibem maiores valores para o índice Bramão et al. (1952) do que a caulinita mais cristalina para o mesmo tamanho de partícula, conforme os valores encontrados Tabela 2.

Os índices de cristalinidade geralmente se correlacionam bem entre si (APARICIO; GALÁN, 1999), no entanto partindo do princípio que um 
determinado índice é mais apropriado do que outro em uma determinada situação essa correlação deverá diminuir (Tabela 3).

Aparentemente o índice de Amigó et al.(1987) é o índice mais adequado para ser utilizado para avaliar simultaneamente a cristalinidade no CCA e CRA, devido a melhor correlação encontrada com aos outros índices (Tabela 3), visto que a temperatura de desidroxilação não é confiável, embora exista correlações significativas entres esta variável e os índices de Amigó et al. (1987), Bramão et al. (1952) e o Hughes e Brown (1979), devido a inversão das temperaturas no CRA e a presença de um pico endotérmico posterior e próximo a desidroxilação da caulinita e haloisita no CCA.

Dentro do CCA seria recomendável usar o índice de Amigó et al. (1987) enquanto dentro do CRA tanto o índice de Amigó et al. (1987) quanto o índice Bramão et al. (1952) são adequados.

Tabela 2 - Cristalinidade do caulim comercial A (CCA) e do caulim rosa arenoso (CRA) nas diferentes frações granulométricas.

\begin{tabular}{clllll}
\hline Materiais & Fração & H e B & LMA & $\alpha / \beta$ & TD $\left({ }^{\circ} \mathrm{C}\right)$ \\
\hline CCA & Af & 48,61 & 0,36 & 1,11 & 521 \\
& Am & 60,90 & 0,31 & 0,97 & 522 \\
& Ag & 84,18 & 0,28 & 0,90 & 527 \\
& Sf & 88,45 & 0,26 & N.C & 527 \\
CRA & Sg & 80,69 & 0,18 & N.C & 530 \\
& Af & 11,00 & 1,34 & 1,33 & 511 \\
& Am & 9,43 & 0,88 & 1,19 & 507 \\
& Ag & 12,11 & 0,87 & 1,16 & 506 \\
& Sf & 11,86 & 0,72 & 1,00 & 501 \\
& Sg & 11,23 & N.C & 0,91 & 495 \\
& A & 12,61 & N.C & 0,93 & 500 \\
\hline
\end{tabular}

H e B: índice de Hughes e Brown; LMA: Índice de Amigó et al; $\alpha / \beta$ : Índice de Bramão et al.; TD: temperatura de desidroxilação da caulinita e haloisita; N.C: não calculado devido à desidratação parcial da haloisita (LMA), a presença do pico endotérmico mica posterior e próximo ao da caulinita que poderia interferir nos resultados $(\alpha / \beta)$; Af: argila fina; Am: argila média; Ag: argila grossa; Sf: silte fino; $\mathrm{Sg}$ : silte grosso; A: areia.

Fonte: Os autores.
Tabela 3 - Matriz de correlação entre os índices de cristalinidade para o CCA, CRA e para o CCA e CRA simultaneamente.

\begin{tabular}{lllll}
\hline Materiais & Índices & LMA & $\alpha / \beta$ & TD \\
\hline \multirow{3}{*}{ CCA e CRA } & HeB & $-76,93^{*}$ & $-17,36$ & $86,02^{*}$ \\
& LMA & & $76,12^{*}$ & $-61,69^{*}$ \\
& $\alpha \beta$ & & & 0,06 \\
\hline \multirow{2}{*}{ CCA } & HeB & $-56,1$ & $-87,15$ & $77,07^{* *}$ \\
& LMA & & $99,78^{*}$ & $-88,49^{*}$ \\
& $\alpha \beta$ & & & $-72,00$ \\
\hline \multirow{2}{*}{ CRA } & HeB & $-3,32$ & $-23,22$ & $-14,15$ \\
& LMA & & $85,5^{* *}$ & $83,51^{* *}$ \\
& $\alpha / \beta$ & & & $93,86^{*}$ \\
\hline
\end{tabular}

HeB: índice de Hughes e Brown; LMA: Índice de Amigó et al.; $\alpha / \beta$ : Índice de Bramão et al.; TD: temperatura de desidroxilação da caulinita e haloisita; * p- valor $<0,05$; ** p- valor $<0,10$.

Fonte: Os autores.

As fórmulas químicas teóricas dos minerais (Tabela 4) identificados nos materiais analisados mostram a predominância dos aluminossilicatos entre os minerais encontrados.

\section{Conclusões}

O fracionamento dos caulins foi eficiente na concentração de minerais em frações específicas do material original. No CCA foi concentrado um mineral ainda não identificado nas mais frações finas, no CRA foi concentrado zircão no silte grosso e diferentes silicatos nas frações mais finas e no caulim CCB foram concentrados caulinita e um silicato nas frações, argila média e argila grossa.

A quantificação dos minerais por DRX é variável em função da presença caulinita ou haloisita, sendo a primeira responsável por superestimar os valores e a última por subestimá-los, quando comparados aos valores obtidos por ATG.

Os índices de cristalinidade apresentam comportamentos distintos em função da mineralogia de cada material, deste modo, correlações entre a cristalinidade da caulinita e/ou haloisita e outras variáveis, podem ser comprometidas, principalmente em materiais com origens geológicas distintas. 
Tabela 4 - Fórmulas químicas dos minerais identificados nos materiais estudados.

\begin{tabular}{ll}
\hline Mineral & Fórmula química \\
\hline & \\
Caulinita & $\mathrm{Al}_{2}\left(\mathrm{Si}_{2} \mathrm{O}_{5}\right)(\mathrm{OH})_{4}$ \\
Haloisita-7A & $\mathrm{Al}_{2}\left(\mathrm{Si}_{2} \mathrm{O}_{5}\right)(\mathrm{OH})_{4}$ \\
Muscovita & $\mathrm{K}_{0,932} \mathrm{Al}_{2}\left(\mathrm{Al}_{0,932} \mathrm{Si}_{3,068} \mathrm{O}_{10}\right)\left((\mathrm{OH})_{1,744} \mathrm{~F}, 0,256\right)$ \\
Glauconita & $\mathrm{K}\left(\mathrm{Fe}, \mathrm{Al}_{2}\left(\mathrm{Si}_{2} \mathrm{Al}_{2}\right)_{4} \mathrm{O}_{10}(\mathrm{OH})_{2}\right.$ \\
Pirofilita & $\mathrm{Al}_{2} \mathrm{Si}_{4} \mathrm{O}_{10}(\mathrm{OH})_{2}$ \\
Montmorilonita & $\mathrm{Na}_{0}, 3(\mathrm{Al}, \mathrm{Mg})_{2} \mathrm{Si}_{4} \mathrm{O}_{10}(\mathrm{OH})_{2} \cdot 4 \mathrm{H}_{2} \mathrm{O}$ \\
Diáspora & $\mathrm{AlO}(\mathrm{OH})$ \\
Alunita & $\mathrm{KAl}_{3}\left(\mathrm{SO}_{4}\right)_{2}(\mathrm{OH})_{6}$ \\
Quartzo & $\mathrm{SiO}_{2}$ \\
Zircão & $\mathrm{ZrSiO}_{4}$ \\
Rutilo & $\mathrm{TiO}_{2}$ \\
Magnetita & $\mathrm{Fe}_{3} \mathrm{O}_{4}$ \\
Bassanita & $\mathrm{CaSO}_{4} \cdot 0,5 \mathrm{H}_{2} \mathrm{O}$ \\
Calcita & $\mathrm{CaCO}_{3}$ \\
Crandalita & $\mathrm{CaAl}_{3}(\mathrm{OH})_{6}\left(\mathrm{PO}_{3}\left(\mathrm{O}_{0,5}(\mathrm{OH})_{0,5}\right)\right)_{2}$ \\
\hline
\end{tabular}

Fonte: Os autores.

\section{Agradecimentos}

Os autores agradecem ao Complexo de Centrais de Apoio à Pesquisa (COMCAP) e ao Departamento de Química da Universidade Estadual de Maringá pelo fornecimento de equipamento para as análises difratometria de raios-X e análise térmica.

\section{Referências}

AMIGÓ, J. M.; BATISTA, J.; GARCÍA AGRAMUT, M. J.; SANZ, M.; GALVÁN, J. Crystallinity of lower cretaceous kaolinite of turuel. In: GALÁN, E.; PÉREZRODRÍGUEZ, J. L.; CORNEJO, J. (Ed.) EUROCLAY CONFERENCE, Sevilla, 1987. Anales... Sevilla, 1987. p. 74-75.

APARICIO, P.; GALÁN, E. Mineralogical interference on kaolinite crystallinity index measurements. Clays and Clay Minerals, New York, v. 47, p. 12-27, 1999.

BAKER, L. L.; REMBER, W. C.; SPRENKE, K. F.; STRAWN, D. G. Celadonite in continental flood basalts of the Columbia River Basalt group. American Mineralogist, Washington, v. 97, p. 1284-1290, 2012.

BRAMÃO, L.; CADY, J. G.; HENDRICKS, S. B.; SWERDLOW, M. Criteria for the characterization of kaolinite, halloysite, and a related mineral in clays and soils. Soil Science, Baltimore, v. 73, n. 4, p. 273-287, 1952
BRINDLEY, G. W. Kaolin, serpentine, and kindred minerals. In: BROWN, G. (Ed.) The X-ray identification and crystal structure of clay minerals. Mineralogical Society: London, 1961. p. 51-131.

BUCKLEY, H. A.; BEVAN, J. C.; BROWN, K. M.; JOHNSON, L. R.; FARMER, V. C. Glauconite and celadonite: two separate mineral species. Mineralogical Magazine, London, v. 42, p. 373-382, 1978.

CAVALHEIRO, E. T. G.; IONASHIRO, M.; BREVIGLIERI, S. T.; MARINO, G.; CHIERICE, G. O. Influência de fatores experimentais nos resultados de análises termogravimétricas, Química Nova, São Paulo, v. 18, p. 305-308, 1995.

CHURCHMAN, G. J.; WHITTON, J. S.; CLARIDGE, G. G. C.; THENG, B. K. G. Intercalation method using formamide for differentiating halloysite from kaolinite. Clays and Clay Minerals, New York, v. 32, p. 241-248, 1984.

COSTA, A. C. S.da; BIGHAM, J. M. Óxidos de ferro. In: MELO, V. F.; ALLEONI, L. R. F. (Ed.). Química e mineralogia do solo. Viçosa: Sociedade Brasileira de Ciência do Solo, 2009. p. 505-572. (Conceitos básicos, v. 1)

DIXON, J. B. Kaolin and serpentine group minerals. In: DIXON, J. B.; WEED, S. B. (Ed.) Minerals in soil environments. 2. ed. Soil Science Society of America: Madison, 1989. p. 467-525.

DIXON, J. B.; MCKEE, T. R. Spherical halloysite formation in a volcanic soil of Mexico. In: INTERNATIONAL CONGRESS OF SOIL SCIENCE, 10., 1974, Moscow. Proceedings... Moscow, 1974.

GRIM, R. E. Clay mineralogy. 2. ed. New York: McGraw-Hill, 1968.

HUGHES, J. C.; BROWN, G. A crystallinity index for soil kaolinite and its relation to parent rock, climate and soil maturity. Journal of Soil Science, Oxford, v. 30, p. 557-563, 1979.

INSTITUTO BRASILEIRO DE MINERAÇÃO IBRAM. Informações e análises da economia mineral brasileira. 6. ed. 2011. Disponível em: http://www. ibram.org.br/sites/1300/1382/00000284.pdf>. Acessado em: 24 mar. 2013.

JACKSON, M. L. Soil Chemical Analysis: advanced course. Madison: Wisconsin, 1975.

JOUSSEIN, E.; PETIT, S.; FIALIPS, C.; VIEILLARD, P.; RIGHI, D. Differences in the dehydratationrehydratation behavior of halloysites: new evidences and interpretations. Clays and Clays Minerals, New York, v. 54, p. 473-484, 2006. 
KARATHANASIS, A. D. Thermal analysis of soil minerals. In: ULERY, A. L.; DREES, L. R. (Ed.). Methods of soil analysis. Madison: SSSA, 2008. p. 117160. (Mineralogical Methods, pt. 5.)

KODAMA, H.; BRYDON, J. E. Dehydroxilation of microcristalline muscovite. Transactions of the Faraday Society, London, v. 64, p. 3112-3119, 1968.

KOHYAMA, N.; FUKUSHIMA, K.; FUKAMI, A. Observation of the hydrated form of tubular halloysite by an electron microscope equipped with an environmental cell. Clays and Clay Minerals, New York, v. 26, p. 25-40, 1978.

LIÈTARD, O. Contribution a l'etude des proprietes physicochimiques, cristallographiques et morphologiques des kaolins. 1977. 243 f. Thèses (Ph. D) - Nancy University, Lorraine, 1977.

LOMBARDI, G. Compositional and structural variations in the size fractions of a sedimentary and a hydrothermal kaolin. Clays and Clay Minerals, New York, v. 35, p. 321-335, 1987.

LUZ, A. B.; CAMPOS, A. R.; CARVALHO, E. A.; BERTOLINO, L. B. ARGILA/CAULIM. In: LUZ, A. B.; LINS, F. A. (Ed.). Rochas e minerais industriais: usos e especificações. Rio de Janeiro: CETEM/MCT, 2005. p. 231-262.

MCRAE, S. G. Glauconite. Earth-Science Reviews, Amsterdam, v. 8, p. 397-440, 1972.

MOORE, J. M.; REYNOLDS JUNIOR, R. C. X-ray diffraction and the identification and analysis of clay minerals. Oxford: Oxford University Press, 1989.

MURRAY, H. H. Applied clay mineralogy: occurrences, processing and applications of kaolins, bentonites, palygorskitesepiolite, and common clays. London: Elsevier, 2007.

MURRAY, H. H.; LYONS, S. C. Further correlation of kaolinite crystallinity with chemical and physical properties. Clays and Clay Minerals, New York, p. 1117,1960 .

ORMSBY, W. C.; SHARTSIS, J. M.; WOODSIDE, K. $\mathrm{H}$. Exchange behavior of kaolins of varying degrees of crystallinity. Journal of the American Ceramic Society, Westerville, v. 45, p. 361-366, 1962.

SMYKATZ-KLOSS, W. Application of differential thermal analysis in mineralogy. Journal of Thermal Analysis, London, v. 23, p. 15-44, 1982.

SMYKATZ-KLOSS, W. Differential thermal analysis. Berlin: Springer-Verlag, 1974.
VELHO, J. A.; GOMES, C. Characterization of Portuguese kaolins for the paper industry: Beneficiation through new delamination techniques. Applied Clay Science, Amsterdam, v. 6, p. 155-170, 1991.

WHITE, G. N.; DIXON, J. B. Kaolin-serpentine mineral. In: DIXON, J. B.; SCHULZE, D. G. (Ed.). Soil Mineralogy with Environmental Applications. Madison: Soil Science Society of America, 2002. p. 389-414.

WHITTING, L. D.; ALLARDICE, W. R. X-ray diffraction techniques. In: KLUTE, A. (Ed.) Methods of soil analysis. Madison: American Society of Agronomy, 1986. p. 331-362.

WILSON, I. R.; SOUZA SANTOS, H.; SOUZA SANTOS, P. Kaolin and halloysite deposits of Brazil Clay Minerals, Clay Minerals, London, v. 4, p. 697-716, 2006.

Recebido em 1 Novembro 2012-Received on November 1, 2012.

Aceito em 19 Abril, 2013 - Accepted on April 19, 2013. 
